\title{
Comparison of biomass estimates from multiple stratification approaches in a swept area method for Pacific saury Cololabis saira in the western North Pacific
}

\author{
Midori Hashimoto ${ }^{1} \cdot$ Hideaki Kidokoro $^{2} \cdot$ Satoshi Suyama $^{3} \cdot$ Taiki Fuji $^{1} \cdot$ Hiroomi Miyamoto $^{3} \cdot$ Miyako Naya $^{3}$. \\ Dharmamony Vijai ${ }^{4}$. Yasuhiro Ueno ${ }^{5} \cdot$ Toshihide Kitakado $^{6}$
}

Received: 1 October 2019 / Accepted: 25 February 2020

(C) The Author(s) 2021, corrected publication 2021

\begin{abstract}
Fishery-independent surveys using sea surface trawl nets for Pacific saury Cololabis saira in the western North Pacific since 2003 have enabled the investigation of their annual distribution patterns and total biomass during June and July, prior to the main fishing season in Japan. We compared biomass estimates and their associated variances derived based on five different post-stratification approaches in a swept area method, and then observed that these approaches have little effect on biomass estimates and their precision, owing to well-organized survey designs and homogeneously allocated sampling stations. We were able to utilize decreasing biomass estimates for 15 years as an essential abundance index in the ongoing stock assessment. Notably, examination based on stratification along with longitudinal survey lines indicated that the estimated biomass had decreased in the western survey area, resulting in an eastward shift in the gravity center of Pacific saury distribution after 2010. We recommend biomass estimation in an east-west direction based on longitudinal stratification as an effective measure to develop population dynamics models which reflect westward migration into the fishing grounds around Japanese coastal waters, and to forecast the expected catch during the subsequent fishing period.
\end{abstract}

Keywords Swept area method · Fishery-independent survey · Pacific saury · Post-stratification · Sea surface trawl net . Stock assessment

Midori Hashimoto

mhashimoto@affrc.go.jp

$1 \quad$ National Research Institute of Far Seas Fisheries, Japan Fisheries Research and Education Agency, 2-12-4 Fukuura, Kanazawa, Yokohama, Kanagawa 236-8648, Japan

2 Tohoku National Fisheries Research Institute, Japan Fisheries Research and Education Agency, 3-27-5, Shinhama, Shiogama, Miyagi 985-0001, Japan

3 Hachinohe Station, Tohoku National Fisheries Research Institute, Japan Fisheries Research and Education Agency, 25-259, Shimomekurakubo, Same, Hachinohe, Aomori 031-0841, Japan

4 National Centre for Biological Science, Tata Institute of Fundamental Research, Bellary Road, Bangalore, Karnataka 560065, India

5 National Research Institute of Fisheries Science, Japan Fisheries Research and Education Agency, 2-12-4 Fukuura, Kanazawa, Yokohama, Kanagawa 236-8648, Japan

6 Tokyo University of Marine Science and Technology, 4-5-7 Konan, Minato-ku, Tokyo 108-8477, Japan

\section{Introduction}

Pacific saury Cololabis saira is a small pelagic fish broadly distributed across the North Pacific Ocean (Hubbs and Wisner 1980). Between April and July, it migrates towards the foraging ground located in its northern habitat (Fukushima 1979) and then presents at least from the Kuroshio-Oyashio transition region to the subarctic region in the west of $165^{\circ} \mathrm{W}$ longitude during summer (Suyama et al. 2016). Subsequently, it migrates westward, reaching the Kuril Islands and Japanese coastal waters between August and December (Suyama et al. 2012; Miyamoto et al. 2019).

The Pacific saury is commercially exploited by Japan, Taiwan, Russia, Korea, Vanuatu, and China, with landings fluctuating between 180,973 metric tons (MT) in 1998 and 631,094 MT in 2014 over the last 30 years [FAO; https:// www.fao.org/fishery/statistucs/software/fishstatistj/en (Accessed 19 July 2019)]. While Japanese and Russian 
fleets operate mainly within their domestic exclusive economic zones from August to December, most other members target Pacific saury mainly in the high seas west of $165^{\circ} \mathrm{E}$ from June to December (Fukushima 1979; Kosaka 2000; Huang 2010). Therefore, this stock has been internationally managed since 2015 by an inter-governmental organization, the North Pacific Fisheries Commission (NPFC), to ensure its long-term conservation and sustainable use. Because the fishing ground is limited in the west side of its habitat, fishery-dependent information is insufficient to elucidate its abundance, distribution, and migratory behavior. Furthermore, an abundance index derived from fishery-dependent information might introduce biases in biomass estimates, because it does not decline in proportion to the decrease of true biomass owing to the concentration of fishing efforts in areas of high density, known as hyperstability (Hilborn and Walters 1992).

To address these issues, annual fishery-independent surveys have been conducted since 2003 on Pacific saury stock from the Japanese coast to $165^{\circ} \mathrm{W}$ in the North Pacific between June and July, immediately preceding the main fishing season (Suyama et al. 2016; Ueno et al. 2017). The resulting information on total biomass and distribution patterns has been utilized for Japanese domestic stock assessment (Suyama et al. 2016), enabling management through forecasting location and timing of fishing grounds formation. Time-series estimates of biomass from the surveys have recently been used internationally as an essential abundance index in a stock assessment by the NPFC (Technical Working Group on Pacific Saury Stock Assessment 2017; 2019).

Total biomass for the Pacific saury in the survey area has been estimated by applying the swept area method to density data collected using sea surface trawl nets (Suyama et al. 2016; Ueno et al. 2017). Generally, sampling locations are randomly allocated within a predetermined stratum with a homogeneous density of target fish in order to minimize internal variance within strata and to enhance overall precision of biomass estimates. Spatial and temporal change in Pacific saury density is likely to occur mainly in conjunction with changes in environmental conditions such as sea surface temperature (SST). However, fixed annual sampling stations are insufficient due to large-scale interannual changes in geographical ranges with suitable SST for the Pacific saury. Sampling coverage of the whole of the potential distribution is also unfeasible due to limited ship time. As an ad-hoc approach, practical locations are conventionally determined based on the observed SST and fish density, facilitating post-stratification of the research area. As mature Pacific saury are found in areas with SST warmer than $15^{\circ} \mathrm{C}$ (Suyama 2002), Ueno et al. (2017) classified the research area as above and below this threshold temperature. Based on this criterion and three main geographic areas (west of $162^{\circ} \mathrm{E}, 162^{\circ} \mathrm{E}-177^{\circ} \mathrm{W}$, and $177^{\circ} \mathrm{W}-165^{\circ} \mathrm{W}$ ), six strata have been adopted in the Japanese domestic stock assessment (Suyama et al. 2016), but lack sufficient scientific basis.

It remains unknown whether these post-stratification approaches are able to effectively perform in biomass estimations of Pacific saury in the western North Pacific, although even provisional approaches can yield useful results owing to a well-organized survey design within such a broad research area. A long time series of data is available, enabling an examination of annual biomass estimates from various stratification approaches. In this study, we investigated density data and measured SST at each surveyed sampling station, to confirm whether these geographical and/or environmental factors were associated with fish density. Next, we estimated the biomass of Pacific saury during the survey period using the swept area method. We then compared the annual biomass estimates and the associated variance between multiple stratification approaches based on factors related to fish density. To provide additional information on Pacific saury distribution during early summer, we also examined annual changes in stratum-specific biomass estimates. Based on this investigation, we discuss and recommend an appropriate approach for future stock assessment and management.

\section{Materials and methods}

\section{Survey designs}

Fishery-independent surveys for Pacific saury were carried out by the Tohoku National Fisheries Research Institute in Japan between June and July during 2003 to 2017 using sea surface trawl nets (NST-99; Nichimo Co., Ltd.). Pacific saury are in the middle of their northward migration during this period and are mainly distributed in the subarctic region (Fukushima 1979; Meguro et al. 1987). The research areas cover the range from Japanese coastal waters to $165^{\circ} \mathrm{W}$ in the North Pacific (Fig. 1). As Pacific saury in the eastern survey area around $175^{\circ} \mathrm{W}$ during the survey period might not migrate to Japanese fishing ground within the same year (Miyamoto et al. 2019), we assume this survey covers the whole habitat of the Pacific saury stock exploited in the western North Pacific. The research area was limited in the west of $177^{\circ} \mathrm{W}$ in 2011 due to research vessel scheduling limitations.

Sampling stations were set along survey lines drawn basically every $4^{\circ}$ longitude. The northern- and southernmost locations were determined based on Pacific saury distribution at $8-18{ }^{\circ} \mathrm{C} \mathrm{SST}$ during the survey period (Odate 1977; Meguro et al. 1987). During each research cruise, the first sampling station on each survey line was set where SST obtained from satellite remote sensing [Fisheries and oceanographic prompt report by Japan Fisheries Information 


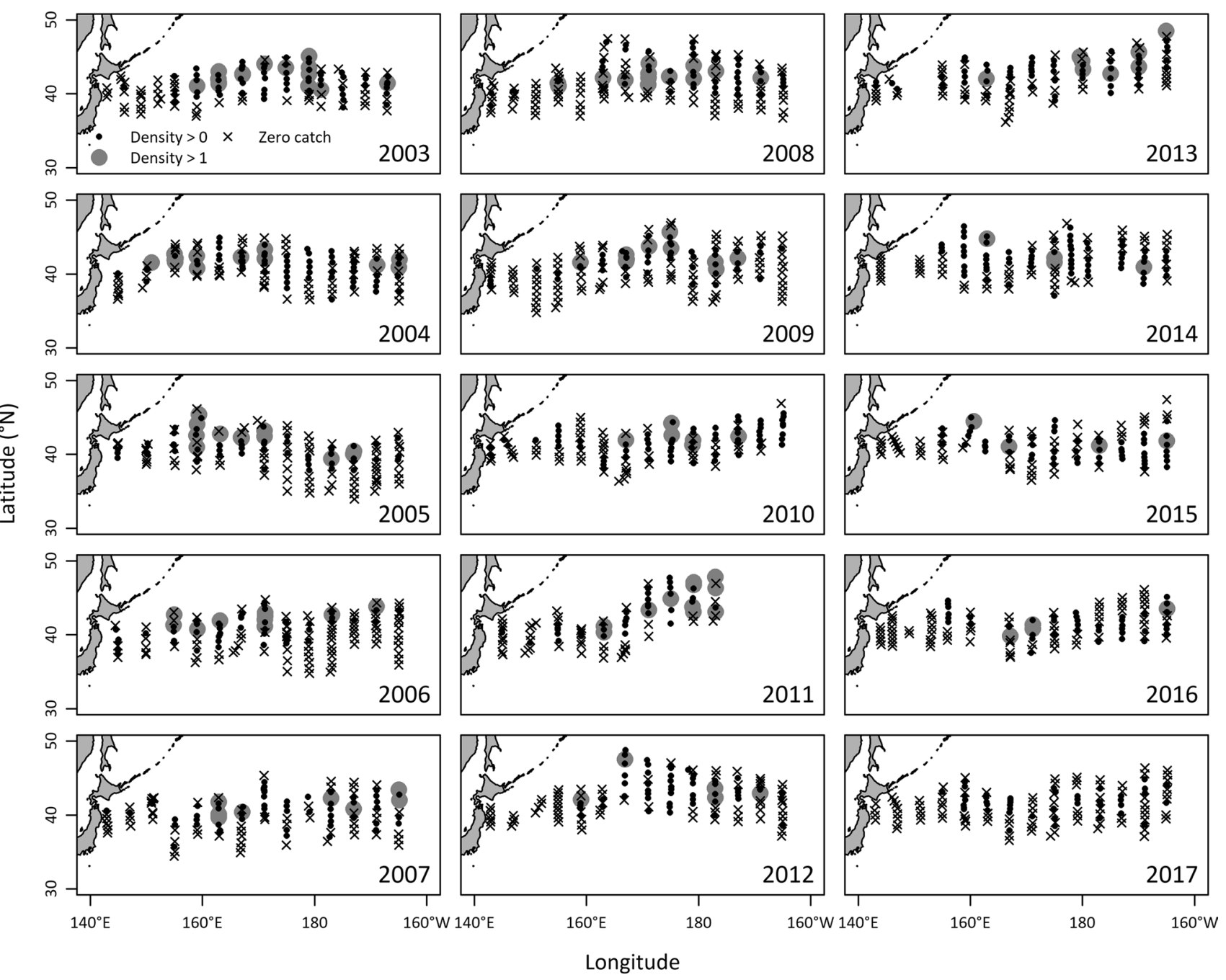

Fig. 1 Locations of sampling stations with density (i.e., catch weight per swept area, MT/ $\mathrm{km}^{2}$ ) in fishery-independent surveys for Pacific saury during 2003 to 2017

Service Center (https://www.jafic.or.jp/publish/index.html) and NOAA's National Weather service (https://tgftp.nws. noaa.gov/fax/hawaii.shtml)] was $\leq 9^{\circ} \mathrm{C}$ or $\geq 17^{\circ} \mathrm{C}$. After the first trawl survey, research vessels moved south or north, respectively, along the longitude line to the next sampling station over $18.5 \mathrm{~km}$ (10 miles) away. Surveys with the movement to the next station were repeated generally until the SST was $\geq 17{ }^{\circ} \mathrm{C}$ or $\leq 9{ }^{\circ} \mathrm{C}$, or rarely until Pacific saury were assumed to be no longer catchable. After completing the survey at the southern- or northernmost station, we then moved to the next southern- or northernmost station on the neighbor survey line where the SST was $\geq 17^{\circ} \mathrm{C}$ or $\leq 9{ }^{\circ} \mathrm{C}$. In some instances, surveys could not be carried out over sufficient range to the north or south due to limited ship time. When this occurred, we moved to the next survey line after confirming whether we investigated near the boundaries of habitat temperature from satellite remote sensing data. Data were collected at more than 100 sampling stations every year excluding 2011, and a total of 1890 collection data were eventually used for analysis (Table 1).

Surface trawls were operated only in daytime, with a warp length of about $200 \mathrm{~m}$ at $4-5$ knots, according to the results of studies on effective sampling of Pacific saury (Ueno et al. 2004, 2017). The maximum and minimum stretched mesh sizes were $15.2 \mathrm{~m}$ and $16.7 \mathrm{~mm}$, respectively. Four research vessels, R/V Wakataka-maru [692 gross tonnage (GRT), Tohoku National Fisheries Research Institute] in 2003, T/S Omi-maru (403 GRT, Yamaguchi Fisheries High School, Yamaguchi Prefecture) from 2003 to 2009, T/S Hokuhomaru (664 GRT, Hokkaido Board of Education) from 2003 to 2017, and R/V Hokko-maru (902 GRT, Hokkaido National Fisheries Research Institute) in 2010 and from 2012 to 2017, were engaged for these surveys. The Hokkomaru had a trawl mouth with $34.7 \mathrm{~m}$ horizontal opening 
Table 1 Annual number of sampling stations and mean area of grids in fishery-independent surveys for Pacific saury during 2003-2017

\begin{tabular}{lrl}
\hline Year & Number of stations & $\begin{array}{l}\text { Mean area of each grid } \\
\text { around station }(1000 \\
\left.\mathrm{km}^{2}\right)\end{array}$ \\
\hline 2003 & 125 & 21.41 \\
2004 & 138 & 22.40 \\
2005 & 135 & 24.96 \\
2006 & 145 & 23.48 \\
2007 & 124 & 25.31 \\
2008 & 143 & 24.31 \\
2009 & 144 & 25.02 \\
2010 & 124 & 22.04 \\
2011 & 92 & 25.53 \\
2012 & 127 & 23.35 \\
2013 & 116 & 25.66 \\
2014 & 122 & 25.76 \\
2015 & 111 & 24.74 \\
2016 & 115 & 23.11 \\
2017 & 129 & 24.31 \\
Total & 1890 & - \\
\hline
\end{tabular}

width, as it used a large otter board with a high expansion capability, while the other three vessels had openings of only $24.0 \mathrm{~m}$. The bottoms of vertical openings of the nets were $20-25 \mathrm{~m}$ in all vessels. Because the Pacific saury is mainly distributed at a depth of around 10-15 m during daytime (Wada and Kitakata 1982), the vertical depth of these nets was assumed to cover its habitat layer.

It should be noted that the complete size range of Pacific saury in the western North Pacific was not targeted by our surveys, despite the complete research area coverage. Larval fish seemed to appear during the surveys, as they included the end of the spawning season from September to June. However, a part of age 0 fish hatched after January did not appear in the survey, as most sampled fish were $>15 \mathrm{~cm}$ (Suyama et al. 2012), and Pacific saury take about 5 months to reach this size (Watanabe et al. 1988; Nemoto et al. 2001; Suyama et al. 2011). We nonetheless took into account the total biomass for age $1 \mathrm{fish}$, as they would reach $25 \mathrm{~cm}$ during the survey period (Suyama et al. 2011, 2012).

Trawling from net setting to hauling took approximately $1 \mathrm{~h}$. Locations of setting and hauling were recorded using GPS. The swept area was calculated as the product of the horizontal opening width and the towing distance between net setting and hauling. SST at each station was measured at each setting or hauling position. We sorted Pacific saury from other netted species and recorded the number of fish and catch weight after each towing. The density of the Pacific saury in MT/ $\mathrm{km}^{2}$ at each sampling station was obtained by dividing the catch weight by the swept area at the station.

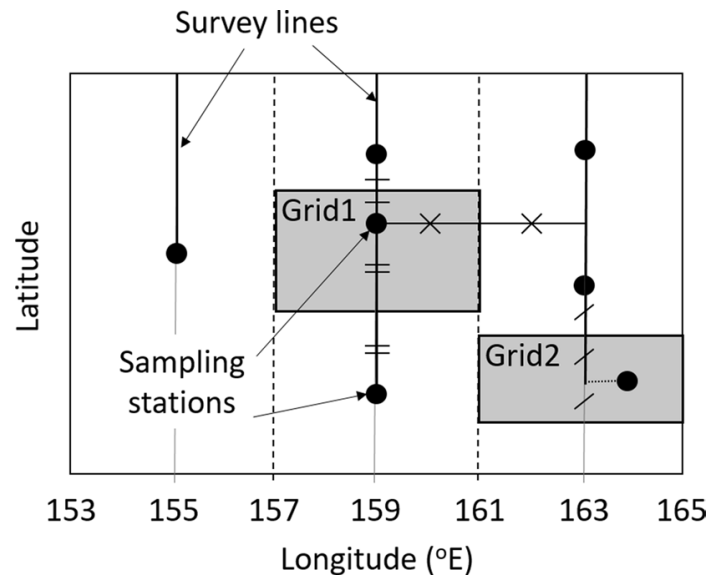

Fig. 2 Diagram of a square grid (shaded area) surrounding a sampling station, with Grid 1 showing a standard sampling station and Grid 2 showing the southernmost station along a survey line. Identical symbols on a line indicate equal distance

\section{Stratification approaches}

Area stratification is an essential part of the swept area method for improving the precision of biomass estimates. In accordance with conventional methods (Suyama et al. 2016; Ueno et al. 2017), we adopted a post-stratification approach based on knowledge of geographical locations and environmental factors which were likely to be associated with fish density. We first investigated the relationship between fish density and factors such as longitude and SST at each sampling station in the fishery-independent survey, then confirmed whether it was reasonable to assume a homogeneous fish density in the strata using these factors.

Next, we set a square grid for every sampling station in order to separate the whole research area and to calculate the area of each strata (Fig. 2). Longitudinal borders were located on the middle lines of the neighbor survey lines, making the east-west grid size principally $4^{\circ}$. Latitudinal borders were on the lines through the midpoint of neighbor sampling stations (Grid 1 in Fig. 2). The distance from the outer border to the northern- or southernmost station was equal to that from the corresponding inner border (Grid 2 in Fig. 2). The annual mean area of one grid fluctuated between $21,410 \mathrm{~km}^{2}$ in 2003 and $25,760 \mathrm{~km}^{2}$ in 2014 (Table 1).

We employed five stratification approaches $(\mathbf{a}-\mathbf{e})$. Examples of stratified areas in 2017 are shown in Fig. 3. In approach a, the research area was separated by the measured SST at each sampling station (Fig. 3a). It is generally assumed that fish density within a habitat depends on water temperature for pelagic fish. A positive relationship between SST and spawning activity of Pacific saury has been reported (Kurita 2006). We therefore selected six strata separated by SST $\left(<10.0^{\circ} \mathrm{C}\right.$, $10.0-11.9{ }^{\circ} \mathrm{C}, 12.0-13.9{ }^{\circ} \mathrm{C}, 14.0-15.9{ }^{\circ} \mathrm{C}, 16.0-17.9^{\circ} \mathrm{C}$, and $\geq 18.0^{\circ} \mathrm{C}$ ). In approach $\mathbf{b}$, the research area was divided 
Fig. 3 Stratification approaches and boundaries demonstrated using survey data in 2017 as an example. Stratification was determined using a sea surface temperature (SST), b three zones in an east-west direction, $\mathbf{c}$ six zones associated with a combination of SST and longitude, d longitudinal survey lines, and e no stratification

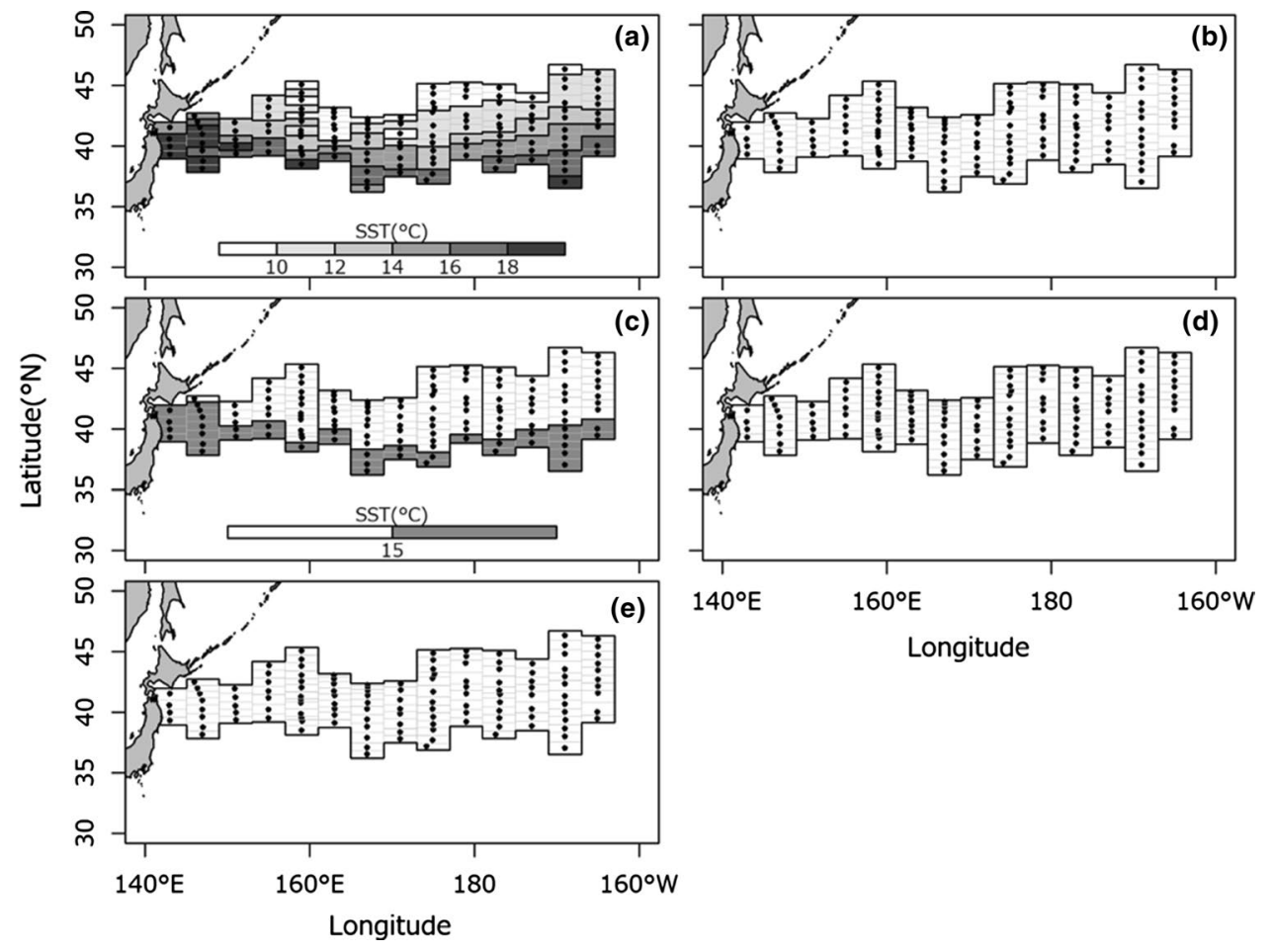

into three zones (Fig. 3b). Although this division followed an east-west direction according to $162^{\circ} \mathrm{E}$ and $177^{\circ} \mathrm{W}$ longitude in the Japanese domestic stock assessment (Suyama et al. 2016), zone borders overlapped on the survey lines, and we could not set grids for stations on these borders. We therefore modified the locations of these borders to avoid the survey lines and consequently defined $161^{\circ} \mathrm{E}$ as the border between zones 1 and 2 and $179^{\circ} \mathrm{W}$ as the border between zones 2 and 3 . In approach c, the research area was divided into six zones along with SST and longitude (Fig. 3c). We considered six strata with the combinations of three zones modified in approach $\mathbf{b}$ and two groups of SST over and under $15^{\circ} \mathrm{C}$, as per a previous study (Ueno et al. 2017). In approach d, the research area was divided into smaller sub-areas along the longitudinal survey lines in order to determine the annual change in Pacific saury distribution during early summer in the east-west direction (Fig. 3d). In approach e, we considered the case without stratification (i.e., whole research area was one stratum) as a control for comparison (Fig. 3e).

\section{Biomass estimation}

Using the swept area method, the annual total biomass $(B)$ of the Pacific saury was estimated as:

$\widehat{B}=\frac{1}{q} \cdot \sum_{i=1}^{N} d_{i} \cdot A_{i}$, where the catchability coefficient $(q)$ of the surface trawl net was given as 0.179 according to Naya et al. (2010), $N$ indicates the total number of strata, and $d_{i}$ and $A_{i}$ respectively represent the mean fish density and the total area in stratum $i$. These were calculated as:

$d_{i}=\frac{1}{n_{i}} \cdot \sum_{j=1}^{n_{i}} d_{i j}$

$A_{i}=\sum_{j=1}^{n_{i}} A_{i j}$

where $n_{i}$ represents the number of sampling stations in stratum $i$, and $d_{i j}$ and $A_{i j}$ are the mean fish density and area at grid $j$ in stratum $i$.

To evaluate uncertainty, the standard error $(S E)$ and coefficient of variation $(\mathrm{CV})$ of the total biomass estimates were calculated as:

$S E=\sqrt{\sum_{i=1}^{N}\left(\frac{A_{i} \cdot S D_{i}}{q \sqrt{n_{i}}}\right)^{2}}$,

$C V=\frac{S E}{\widehat{B}}$

where $S D_{i}$ represents the standard deviation of the mean fish densities in stratum $i$. Confidence intervals for biomass 
estimates in every year were evaluated by replicating biomass estimation from 1000 bootstrap data sets randomly resampled from the original sampling stations in each stratum.

Finally, we compared biomass estimates and their variance among the five stratification approaches. Additional investigation of annual changes in fish density and biomass for each survey line was implemented to clarify the distribution in the east-west direction across the research area.

\section{Results}

\section{Relationship between longitude/SST and fish density}

Pacific saury were broadly distributed in the research area and were caught at 901 of a total 1890 sampling events (Fig. 1). The density at each station tended to differ along an east-west direction (Fig. 4a). The top ten densities were observed in the stations between $150^{\circ} \mathrm{E}$ and 180 . The mean density for stations where Pacific saury were present at intervals of $10^{\circ}$ represented the maximum value of $0.60 \mathrm{MT} / \mathrm{km}^{2}$
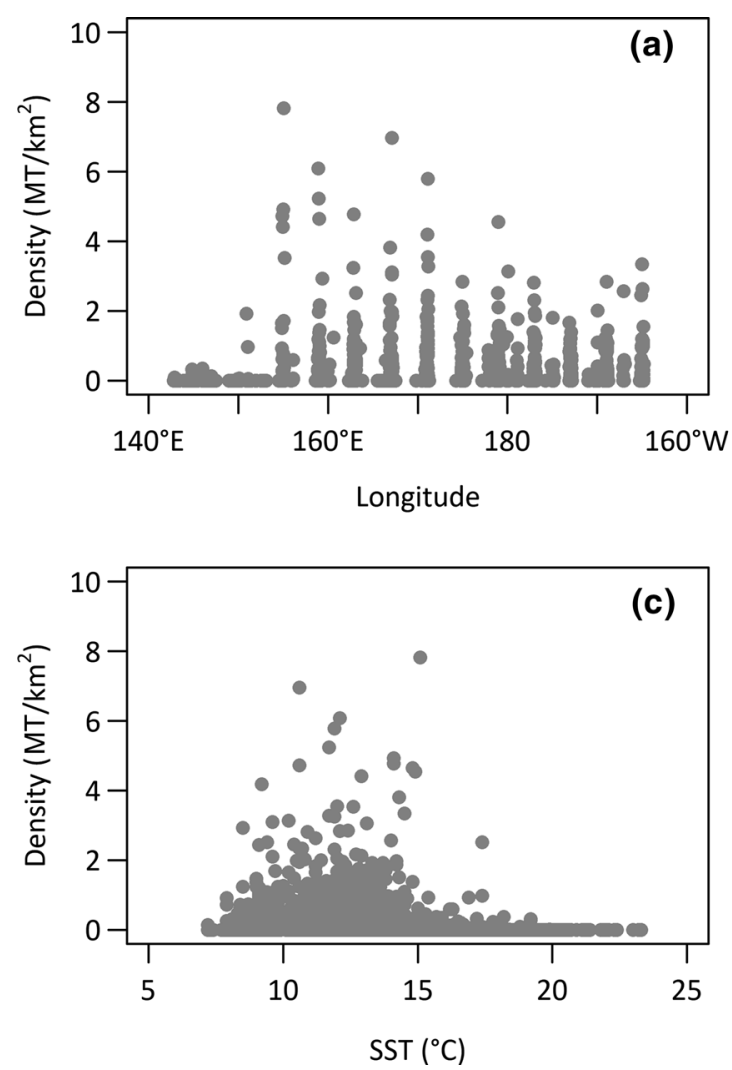

Fig. 4 Relationship between Pacific saury density and $\mathbf{a}$, b longitude and c, d SST in fishery-independent surveys during 2003 to 2017. Plots of $\mathbf{a}, \mathbf{c}$ indicate whole sampling stations and $\mathbf{b}, \mathbf{d}$ indicate annual between $150^{\circ}$ and $160^{\circ} \mathrm{E}$, while gradually decreasing further east. In the western area at $150^{\circ} \mathrm{E}$, even the highest density of $0.34 \mathrm{MT} / \mathrm{km}^{2}$ was considerably lower than in the eastern part. Over the course of the study, annual density-weighted longitude moved slightly eastward, accompanied by shrinkage of areas where Pacific saury were present (Fig. 4b).

Similarly, measured values of SST affected density (Fig. 4c). SST was between $7.2^{\circ} \mathrm{C}$ and $19.9^{\circ} \mathrm{C}$ at stations where Pacific saury were caught, and was $<15{ }^{\circ} \mathrm{C}$ at most stations with density over $1 \mathrm{MT} / \mathrm{km}^{2}$. Both the sea area where Pacific saury were caught and the density-weighted SST values fluctuated annually, without larger trends, across the survey duration (Fig. 4d).

\section{Biomass estimates and their uncertainty}

No apparent differences in estimates of total biomass in the survey area were observed among stratification approaches, and an obvious decrease was indicated in all estimates (Fig. 5). The CV for estimated biomass ranged between $17.1 \%$ and $32.9 \%$ (Table 2), with mean CV of $22.9 \%, 23.3 \%$, $22.7 \%, 23.1 \%$, and $23.6 \%$ for stratification approaches a-e,
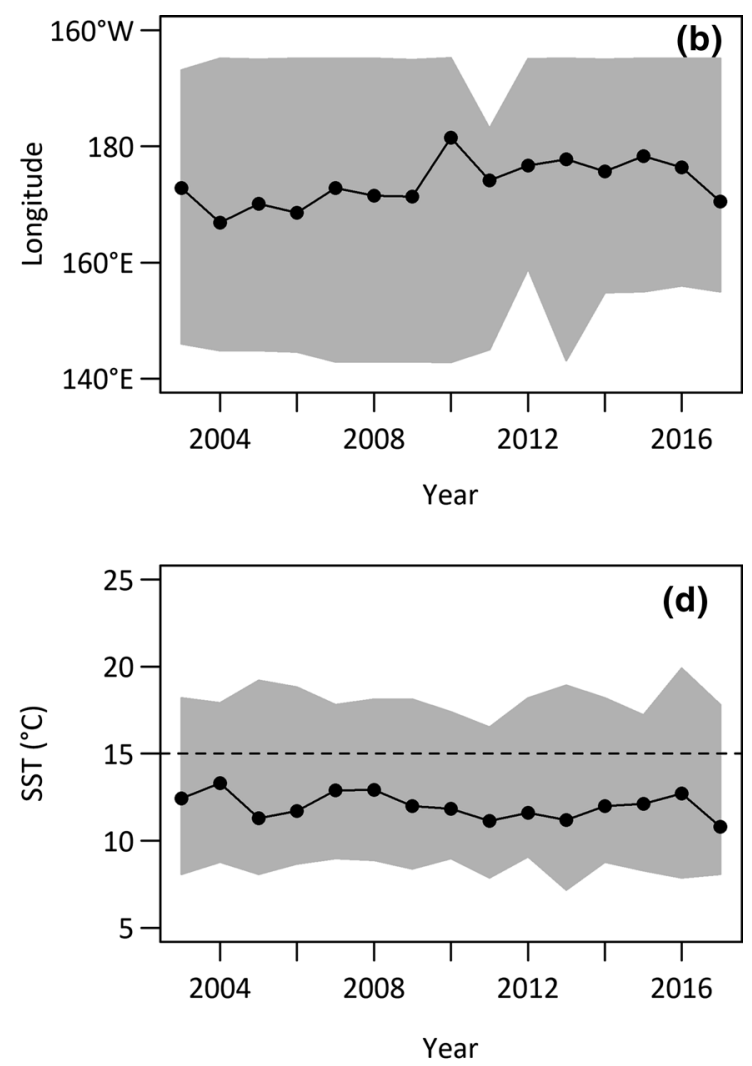

changes in density-weighted longitude/SST (lines) and ranges with the presence of saury (shaded area) 


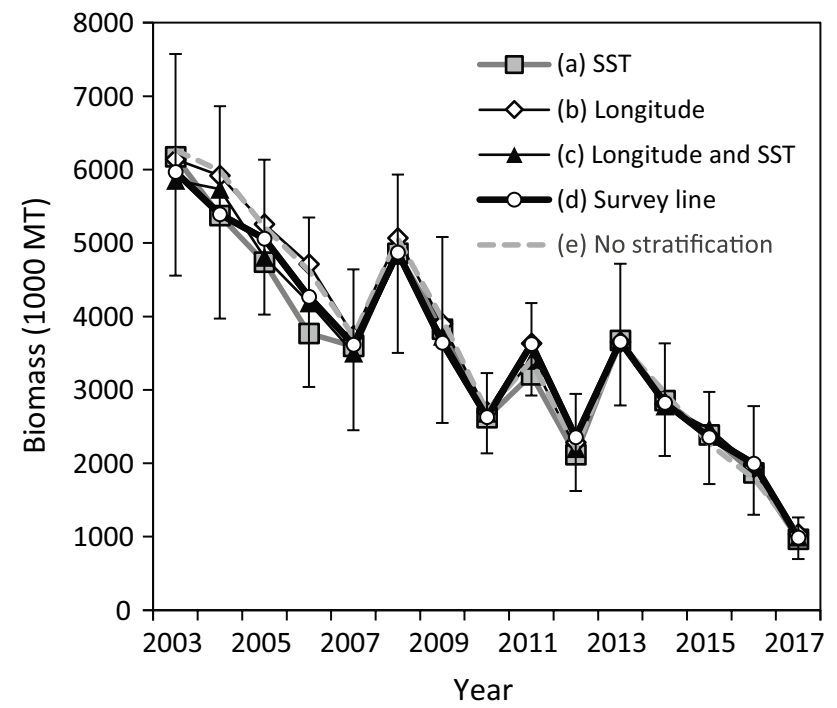

Fig. 5 Comparison of annual changes in biomass estimates according to five stratification approaches (a-e) (see Fig. 3) with $90 \%$ confidence intervals for approach (d)

respectively. There were no apparent differences among stratification approaches.

\section{Annual change in biomass estimates on every longitudinal survey line}

Different year trends in biomass estimates and mean density were observed among the strata along the longitudinal survey lines (Fig. 6). Both biomass and density in the strata on $143^{\circ} \mathrm{E}, 147^{\circ} \mathrm{E}$, and $151^{\circ} \mathrm{E}$ were considerably lower than those in the eastern strata. Maximum biomass of 1,865,000 MT in 2004, 1,215,000 MT in 2005, and 1,412,000 MT in 2003 in respective strata at $155^{\circ} \mathrm{E}, 159^{\circ} \mathrm{E}$, and $167^{\circ} \mathrm{E}$ fluctuated considerably and decreased before 2010, and have remained low since 2010. In contrast, higher biomass estimates were sometimes obtained after 2010 in strata on $175^{\circ} \mathrm{E}$ and $179^{\circ} \mathrm{E}$. In the eastern strata of $177^{\circ} \mathrm{W}$, biomass estimate and mean density varied slightly at a low level, with no apparent trends.

\section{Discussion}

Our surveys indicate that Pacific saury are widely distributed across the western half of the North Pacific Ocean and preferably inhabit water with SST of $7-15{ }^{\circ} \mathrm{C}$ during the survey period in June and July. Density was significantly associated with both longitude and SST, and therefore both variables were expected to perform effectively in the process of area stratification. Although overall density tended to decrease to the west, the longitudinal location of peak density shifted annually (Fig. 7). There was little change in the relationship between SST and fish density over time (Fig. 8).

The various stratification approaches yielded no apparent difference in biomass estimates, particularly after 2006. The stratification into only three sub-areas in approach $\mathbf{b}$ yielded the closest estimates to the control case e. In contrast, the stratification approach a using measured SST yielded slightly lower estimates from 2004 to 2006. This may have occurred because the area ratio of two strata with SST $>16{ }^{\circ} \mathrm{C}$ (and lower fish density) to the whole area was over 35\% during those years, and was higher than the mean $27.7 \%$ during the 15 -year period. Moreover, the precision of these biomass estimates did not differ substantially among stratification approaches. Well-organized survey designs covering a broad research area and homogeneously allocated sampling stations seem to contribute robustness in biomass estimation. Although the obtained values of CV around 23\% were underestimated because they did not include variance in the estimate of catchability coefficient, they are sufficiently low compared with CVs of 13.8-50.3\% in the abundance index estimates without considering catchability in mid-water trawling and swept area method for jack mackerel Trachurus japonicus (Shimura et al. 2009).

We also found that the estimated total biomass of Pacific saury in the survey area has been decreasing annually regardless of the stratification approaches. These estimates could be useful as an essential abundance index in ongoing stock assessment. Meanwhile, the significance of the decreasing trend in biomass estimates needs to be carefully assessed, because annual changes in the catchability coefficient may occur with different research vessels and size selectivity of fishing gear, but was not incorporated. Naya et al. (2010) suggested the possibility that overestimation of the catchability coefficient might yield underestimated biomass, and time-varying catchability could also affect biomass estimates. The previously estimated catchability coefficient of sea surface trawling is beyond the scope of this study, but additional investigations could contribute to the accuracy of biomass estimates.

The immediate cause of the observed stock decline remains to be revealed. Previous studies have indicated a relationship between decadal variation in abundance of Pacific saury and climate change (Tian et al. 2004; Liu et al. 2019), and our research period is likely to correspond to the declining phase of this species suggested in these studies. Furthermore, as Pacific saury habitat overlaps with that of other pelagic species, including Japanese sardine Sardinops melanostictus and chub mackerel Scomber japonicas (Furuichi et al. 2019; Yukami et al. 2019), the competition for food resources may also affect density. Investigations into the relationship between oceanographic conditions and population dynamics among pelagic fishes, as mentioned for Japanese anchovy Engraulis japonicus and Japanese sardine 


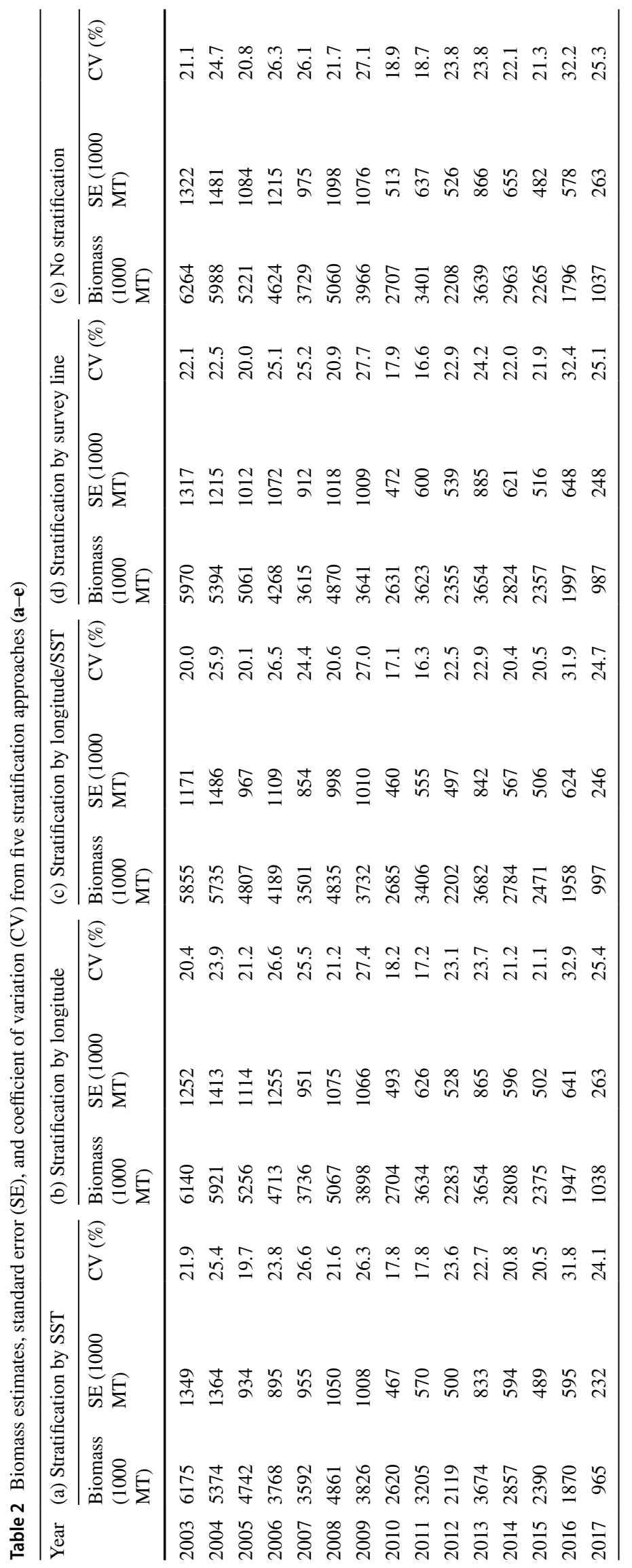



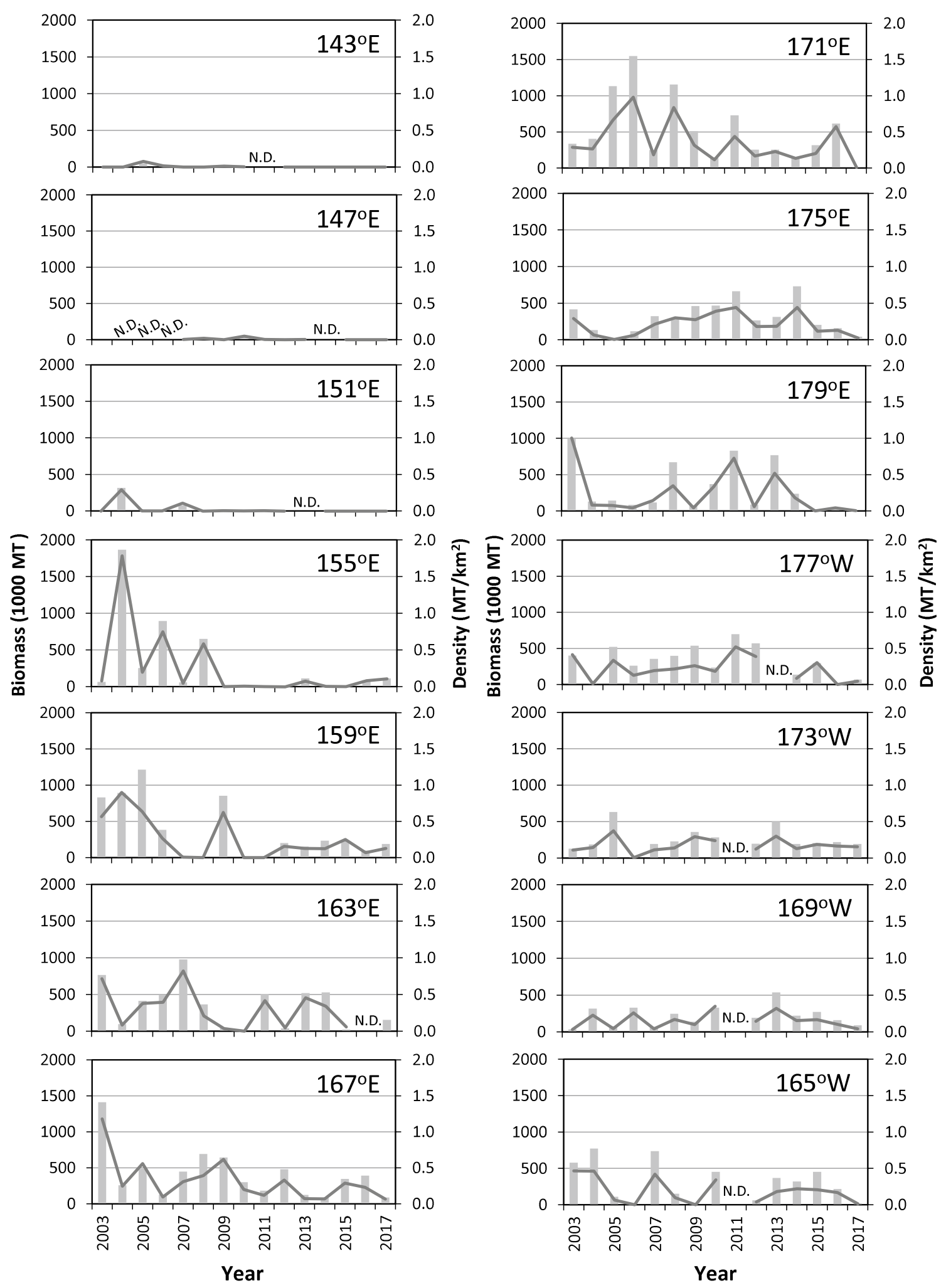

Fig. 6 Annual changes in density (lines) and biomass estimates (columns) in every stratum along a longitudinal survey line 
in the western North Pacific (Nakayama et al. 2018), would help to improve stock assessment for Pacific saury.

The high performance of all biomass estimate methods suggests that researchers can select any of the examined stratification approaches depending on its intended use. The availability of each stratification approach for future stock assessment and management is described below. Because the optimal habitat of pelagic fish is generally associated with SST, an approach based on this measure would appear reasonable. SST is likely to actually constrain the presence of Pacific saury in the research area. The stratification according to SST performed well, although it was not the best-performing method in terms of precision of biomass estimates. On the other hand, stratification along longitudinal survey lines was an effective measure for assessing the distribution of Pacific saury in an east-west direction. For instance, an increase in estimated biomass was observed in the $175^{\circ}$ and $179^{\circ} \mathrm{E}$ strata in some years after 2010, even while biomass fell before 2010 and remained low after that, particularly in the $155^{\circ}$ and $159^{\circ} \mathrm{E}$ strata. These detailed descriptions support the eastward shift in the gravity center of Pacific saury distribution during their northward migration. In addition, monitoring both annual total biomass and annual fluctuation of longitudinal distribution would help to predict expected catch for the subsequent fishing periods. Pacific saury are distributed around the research area during June to July, then migrate into the Japanese coastal sea during August to December, the main Japanese fishing period. Quantitative prediction might become feasible because the immigration rate is constant annually (Miyamoto et al. 2019), and therefore fish in the western area are recruited first to the fishing ground, followed by fish in the eastern area (Suyama et al. 2012; Miyamoto et al. 2019). Accordingly, since 2010, Pacific saury landings in Japan have been smaller at the beginning of the fishing period, then
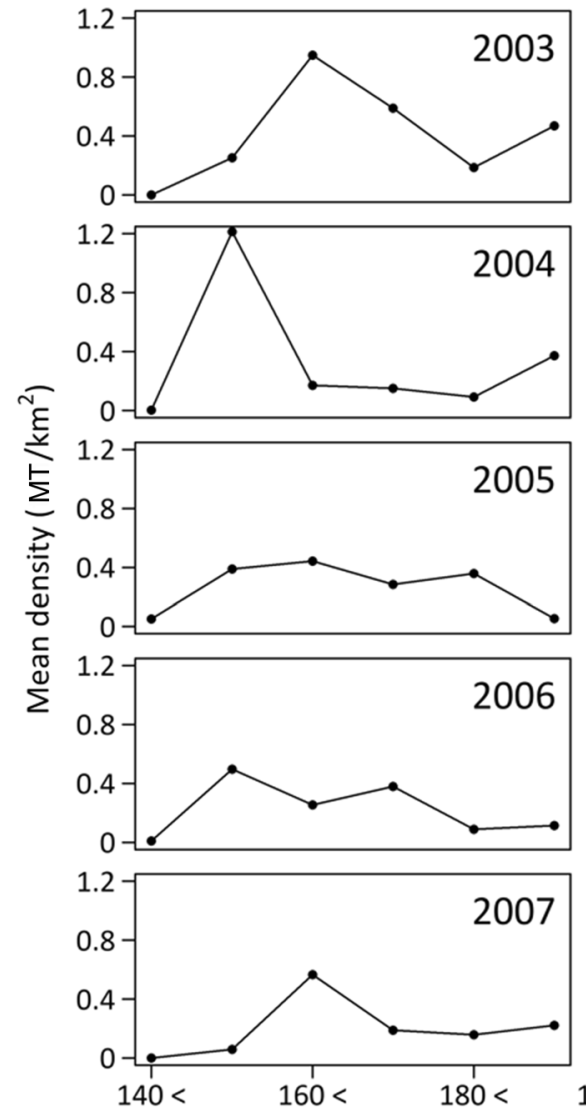
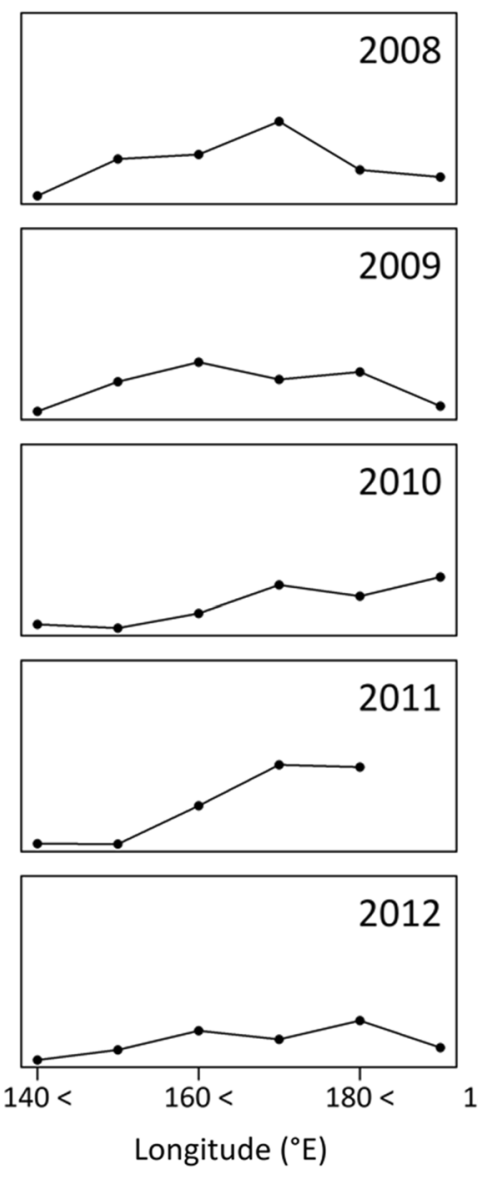
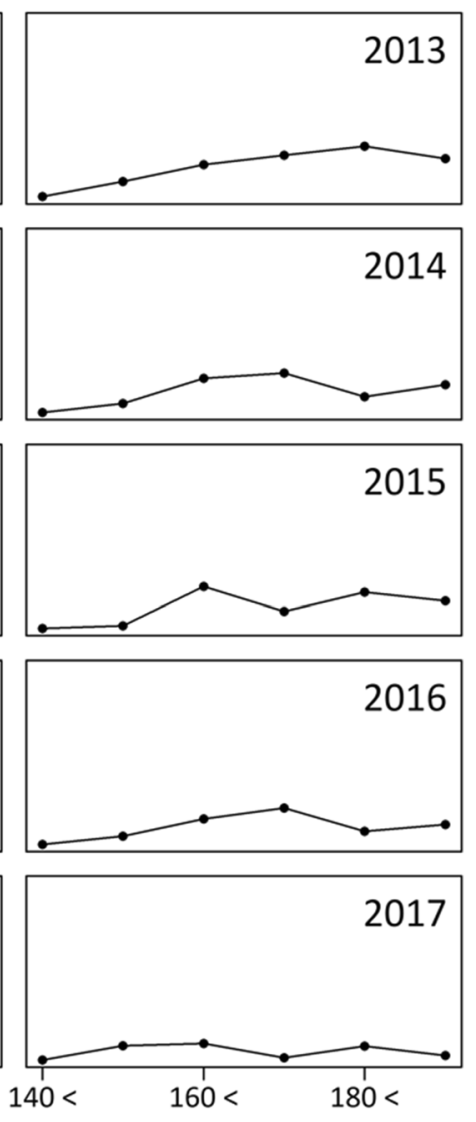

Fig. 7 Annual changes in the relationship between longitude and Pacific saury density observed in fishery-independent surveys 

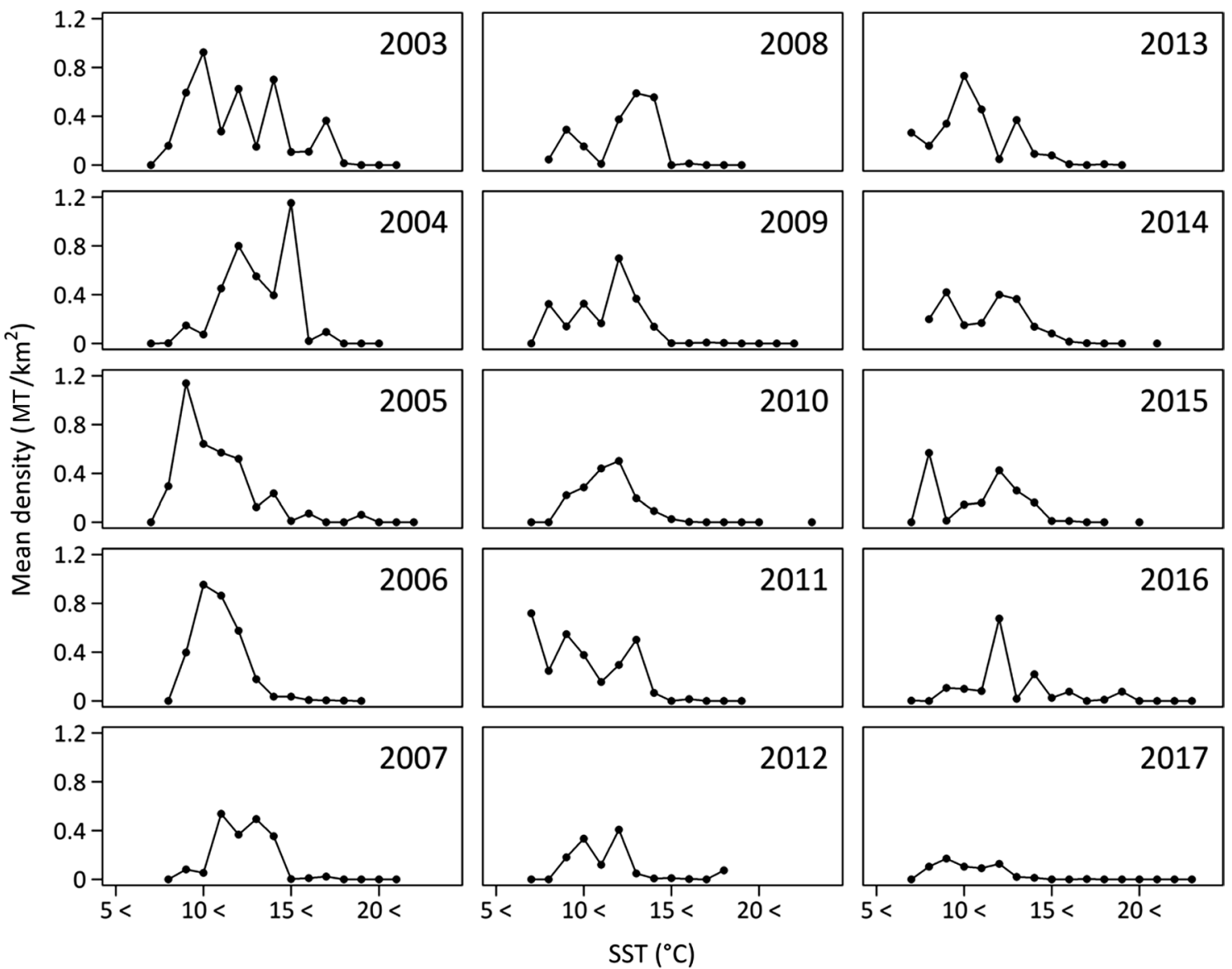

Fig. 8 Annual changes in the relationship between SST and Pacific saury density observed in fishery-independent surveys

increase until mid-September. These wide-ranging images of migration would be available for the development of population dynamics models reflecting spatiotemporal immigration, so as to improve stock assessment and management of Pacific saury in the future.

\section{Appendix}

See Figs. 7, 8.

Acknowledgements We thank the captains and crews on the Hokuhomaru from the Hokkaido Board of Education, T/S Omi-maru from Yamaguchi Prefecture, R/V Wakataka-maru from Tohoku National Fisheries Research Institute, and R/V Hokko-maru from Hokkaido National Fisheries Research Institute for their cooperation in collecting valuable data. Members of the technical working group on Pacific saury stock assessment in the NPFC gave us a great deal of constructive advice for developing our investigation. We appreciate Dr. Toshihide Iwasaki and two anonymous reviewers for valuable comments on our manuscript. This study was supported by the Fisheries Agency of Japan.
Open Access This article is licensed under a Creative Commons Attribution 4.0 International License, which permits use, sharing, adaptation, distribution and reproduction in any medium or format, as long as you give appropriate credit to the original author(s) and the source, provide a link to the Creative Commons licence, and indicate if changes were made. The images or other third party material in this article are included in the article's Creative Commons licence, unless indicated otherwise in a credit line to the material. If material is not included in the article's Creative Commons licence and your intended use is not permitted by statutory regulation or exceeds the permitted use, you will need to obtain permission directly from the copyright holder. To view a copy of this licence, visit http://creativecommons.org/licenses/by/4.0/.

\section{References}

Fukushima S (1979) Synoptic analysis of migration and fishing conditions of saury in the northwest Pacific Ocean. Bull Tohoku Reg Fish Res Lab 41:1-70 (in Japanese with English abstract)

Furuichi S, Watanabe C, Yukami R, Kamimura Y, Isu S (2019) Stock assessment and evaluation for the Pacific stock of Japanese sardine (fiscal year 2018), pp 14-56 in Marine fisheries stock assessment and evaluation for Japanese waters (fiscal year 2018/2019), 
Fisheries Agency of Japan and Fisheries Research and Education Agency of Japan, https://abchan.fra.go.jp/ (in Japanese)

Hilborn R, Walters CJ (1992) Quantitative fisheries stock assessment: Choice, dynamics and uncertainty. Chapman and Hall, London

Huang WB (2010) Comparisons of monthly and geographical variations in abundance and size composition of Pacific saury between the high-seas and coastal fishing grounds in the north- western Pacific. Fish Sci 76:21-31

Hubbs CL, Wisner RL (1980) Revision of the sauries (Pisces, Scomberesocidae) with descriptions of two new genera and one new species. Fish Bull 77:521-566

Kosaka S (2000) Life history of the Pacific saury Cololabis saira in the northwest Pacific and consideration on resource fluctuations based on it. Bull Tohoku Natl Fish Res Inst 63:1-96 (in Japanese with English abstract)

Kurita Y (2006) Regional and interannual variations in spawning activity of Pacific saury Cololabis saira during northward migration in spring in the north-western Pacific. J Fish Biol 69:846-859

Liu S, Liu Y, Fu C, Yan L, Xu Y, Wan R, Li J, Tian Y (2019) Using novel spawning ground indices to analyze the effects of climate change on Pacific saury abundance. J Mar Syst 191:13-23

Meguro T, Anma G, Kajiwara Y, Yamaguchi H, Yamamoto S, Shimazaki K (1987) On the distribution of the Pacific Saury, Cololabis saira BREVOORT, in the Northwestern Pacific Ocean. Hokkaido Univ Collect Sch Acad Pap 38:126-138 (in Japanese with English abstract)

Miyamoto H, Suyama S, Vijai D, Kidokoro H, Naya M, Fuji T, Sakai M (2019) Predicting the timing of Pacific saury (Cololabis saira) immigration to Japanese fishing grounds: a new approach based on natural tags in otolith annual rings. Fish Res 209:167-177

Nakayama S, Takasuka A, Ichinokawa M, Okamura H (2018) Climate change and interspecific drive species alternations between anchovy and sardine in the western North Pacific: Detection of causality by convergent cross mapping. Fish Oceanogr 27:312-322

Naya M, Ueno Y, Mouri T, Oshima K, Watanabe T, Fujita K, Itoh K, Iwasaki K, Matsuo Y, Itoh Y, Shimizu Y (2010) Estimation of the fishing efficiency of a mid-water trawl for Pacific saury Cololabis saira using a high-frequency side-scan sonar. Nippon Suisan Gakkaishi 76:658-669 (in Japanese with English abstract)

Nemoto Y, Kurita Y, Oozeki Y, Honma T, Hayashizaki K, Ida H (2001) Otolith microstructure of Pacific saury, Cololabis saira. Bull Tohoku Natl Fish Res Inst 64:69-78 (in Japanese with English abstract)

Odate S (1977) On the distribution of Pacific saury in the north Pacific Ocean. Special Bulletin of Research Institute of North Pacific Fisheries Hokkaido University: 353-381 (in Japanese with English abstract)

Shimura T, Ohshimo S, Terakado H, Tian Y (2009) Development of method for estimation of $0+$ fish abundance index of jack mackerel Trachurus japonicus by mid-water trawling and area-swept method in the southwestern Sea of Japan. Nippon Suisan Gakkaishi 75:1042-1050 (in Japanese with English abstract)

Suyama S (2002) Study on the age, growth, and maturation process of Pacific saury Cololabis saira (Brevoort) in the North Pacific. Bull Fish Res Agency 5:68-113 (in Japanese with English abstract)

Suyama S, Oshima K, Nakagami M, Kawabata A (2011) Seasonal changes in otolith and somatic growth in age-0 Pacific saury, Cololabis saira. Fish Sci 77:223-233

Suyama S, Nakagami M, Naya M, Ueno Y (2012) Migration route of Pacific saury Cololabis saira inferred from the otolith hyaline zone. Fish Sci 78:1179-1186

Suyama, S, Nakagami M, Naya M, Kato Y, Shibata Y, Sakai M, Takeuchi Y (2016) Stock assessment and evaluation for northwestern Pacific stock of Pacific saury (fiscal year 2015), pp. 283-336 in Marine fisheries stock assessment and evaluation for Japanese waters (fiscal year 2015/2016), Fisheries Agency and Fisheries Research Agency of Japan (in Japanese)

Technical Working Group on Pacific Saury Stock Assessment (2017) 1st Meeting Report. NPFC-2017-TWG PSSA01-Final Report. 120 pp. (www.npfc.int)

Technical Working Group on Pacific Saury Stock Assessment (2019) 4th Meeting Report. NPFC-2019-TWG PSSA04-Final Report. 50 pp. (www.npfc.int)

Tian Y, Ueno Y, Suda M, Akamine T (2004) Decadal variability in the abundance of Pacific saury and its response to climatic/oceanic regime shifts in the northwestern subtropical Pacific during the last half century. J Mar Syst 52:235-257

Ueno Y, Suyama S, Kurita Y, Kumazawa T (2004) Design and operation methods of a mid-water trawl for quantitative sampling of a surface pelagic fish, Pacific saury (Cololabis saira). Fish Res 66:3-17

Ueno Y, Suyama S, Nakagami M, Naya M, Sakai M, Kurita Y (2017) Direct estimation of stock abundance of Pacific saury Cololabis saira in the northwestern Pacific Ocean using a midwater trawl. Fish Sci 83:23-33

Wada T, Kitakata M (1982) Sampling research with mid-water drift gillnet and behavior of saury in the daytime. Bull Hokkaido Reg Fish Lab 47:11-22 (in Japanese with English abstract)

Watanabe Y, Butler JL, Mori T (1988) Growth of Pacific saury, Cololabis saira, in the northeastern and northwestern Pacific Ocean. Fish Bull 86:489-498

Yukami R, Nishijima S, Isu S, Watanabe C, Kamimura Y, Furuichi S (2019) Stock assessment and evaluation for the Pacific stock of chub mackerel (fiscal year 2018), pp 163-208 in Marine fisheries stock assessment and evaluation for Japanese waters (fiscal year 2018/2019), Fisheries Agency of Japan and Fisheries Research and Education Agency of Japan, https://abchan.fra.go.jp/ (in Japanese)

Publisher's Note Springer Nature remains neutral with regard to jurisdictional claims in published maps and institutional affiliations. 